\title{
Kejadian Low Back Pain pada Mekanik Bagian UPT Mekanisasi di Dinas Tanaman Pangan dan Hortikultura Provinsi Riau
}

\section{Occurrence of Low Back Pain in The Mechanical Part UPT Mechanization in Crops And Horticulture Department of Riau Province}

\author{
Kursiah Warti Ningsih, Dwi Sapta A, Rudi Fernando
}

STIKes Payung Negeri Pekanbaru

\begin{abstract}
Low Back Pain (LBP) adalah nyeri yang dirasakan di daerah punggung bawah, dapat merupakannyeri lokal (inflamasi), maupun nyeri radikuler atau keduanya. Low back pain merupakan penyakit yang paling banyak dialami pekerja, dimana kejadian nyeri punggung bawah tidak mengenal perbedaan umur, jenis kelamin, pekerjaan, status sosial, maupun tingkat pendidikan/pengetahuan, semua dapat terkena. Lebih dari $70 \%$ manusia dalam kehidupannya pernah mengalami nyeri punggung bawah, dengan rata-rata puncak kejadian berusia 35-55 tahun. Penelitian ini dilakukan di Dinas Tanaman Pangan dan Hortikultura Provinsi Riau pada bulan Juli 2014.Desain Penelitian adalah cross sectional dengan jumlah responden sebanyak 32 pekerja. Pengumpulan data low back pain dilakukan dengan intrumen berupa body mapping checklist, dan intrumen pengumpulan variabel pengetahuan, masa bekerja dan umur pekerja dengan kuesionersebagai alat bantu dalam pengumpulan data. Analisis data yang menggunakan uji regresi linier. Hasil penelitian ini menunjukan bahwa ada hubungan yang signifikan antara umur pekerja dan masa kerja dengan kejadian low back pain.Hasil ini menunjukkan bahwa peningkatan 1 poin umur pekerja maka akan terjadi peningkatan 0,084 poin low back pain pada pekerja dan peningkatan 1 poin masa kerja maka akan terjadi peningkatan 0,097 poin low back pain pada pekerja. Disarankan kepada Dinas Tanaman Pangan dan Holtikultura Provinsi Riau untuk mengadakan senam pagi setiap minggunya guna memperkuat masa tulang, menurunkan nyeri sendi kronis pada pinggang, punggung dan lutut mengingat kejadian low back pain ini berhubungan dengan umur dan masa kerja.
\end{abstract}

Kata Kunci : Low back pain, Umur, Pengetahuan Tentang Postur Kerja, Masa Kerja

\section{ABSTRACT}

Low Back Pain (LBP) is pain felt in the lower back area, may be a local pain (inflammation), or radicular pain or both. Low back pain is a disease that most experienced workers, where the incidence of lower back pain knows no differences in age, sex, occupation, social status, or level of education / knowledge, can all be affected. More than $70 \%$ of people in his life ever experienced lower back pain, with an average peak incidence 35-55 years old. This research was conducted at the Department of Food Crops and Horticulture Riau province in July 2014. The study design was cross-sectional with a number of respondents as many as 32 workers. The data collection is done with low back pain in the form of body mapping instrument checklist, and instrument variables collection of knowledge, work period and age of workers with the questionnaire as a tool in data collection. Analysis of the data using linear regression. These results indicate that there is a significant relationship between the worker's age and years of service with the incidence of low back pain. These results indicate that an increase of 1 point the worker's age there will be an increase of 0,084 points low back pain on workers and an increase of 1 point tenure there will be an increase of 0.097 points low back pain in workers. Suggested to the Department of Food Crops and Horticulture Riau province to hold a morning exercise every week to strengthen bone mass, decrease chronic joint pain in the waist, back and knee recalling the events of low back pain is related to age and work period.

Keywords: Low back pain, Age, Knowledge AboutWork posture, Work Period

\section{PENDAHULUAN}

Pada era globalisasi ini peranan manusia sebagai sumber tenaga kerja masih dominan dalam menjalankan proses produksi terutama kegiatan yang bersifat manual. Aktivitas manusia seperti ini dapat menyebabkan masalah ergonomi yang sering dijumpai di tempat kerja khususnya yang berhubungan dengan kekuatan dan ketahanan manusia dalam melakukan pekerjaannya. Keluhan yang sering timbul pada pekerja industry adalah nyeri punggung, nyeri leher,

${ }^{1}$ Alamat Korespondensi : Dwi Sapta A, Email: ihsanyuldi@gmail.com 
serta nyeri pada pergelangan tangan, siku dan kaki.Ada 4 faktor yang dapat meningkatkan timbulnya keluhan ini, yaitu postur yang tidak alamiah, tenaga yang berlebihan, pengulangan berkali-kali, dan lamanya waktu kerja. Parah ataupun tidak keluhan ini, tetap saja dapat menggangu konsentrasi dalam bekerja, serta menimbulkan kelelahan dan pada akhirnya akan menurunkan produktivitas (Kurniawati, 2013).

Menurut Anderson (2007) dalam Rinta (2013) dari beberapa laporan dan hasil penelitian yang pernah dilakukan menyebutkan bahwa penyakit akibat kerja khususnya low back pain(LBP) yang disebut juga nyeri punggung bawah (NPB) merupakan penyakit yang paling banyak dialami pekerja,dimana kejadian ini tidak mengenal perbedaan umur, jenis kelamin, pekerjaan, status sosial,maupun tingkat pendidikan/pengetahuan, semua dapat terkena. Lebih dari $70 \%$ manusia dalam kehidupannya pernah mengalami NPB, dengan rata-rata puncak kejadian berusia 35-55 tahun.

Di Amerika dan Australia low back pain merupakan satu darisepuluh keluhan utama dan dilaporkan prevalensi nyeri punggung bawah berkisardi antara 26,4\% - 79,2\% (US National Survey, 2002 dalam Johannes, 2010).Pada tahun 2007 di Belanda, nyeri punggung mengakibatkan kerugian sebesar €3534 jutapound sterling, dan menyebabkan kehilangan waktu kerja sebanyak 6.057.140 hari.Pada tahun 1997 LBP dilaporkan berdampak pada perindustrian di Amerika sebesar \$171 juta.Kebanyakan kejadian LBP dikaitkan dengan jenis pekerjaan seperti mengangkat.(Halimah, 2011).

Berdasarkan penelitian Picavet dan Schouten (2001) dalam Halimah (2011) yang dilakukan pada 8.000 orang sampel yang berumur 25 tahun ke atas di Belanda dengan desain penelitian kohort, hampir tiga perempat $(74,5 \%)$ penduduk Belanda yang berumur 25 tahun ke atas dilaporkan menderita nyeri muskoskeletal dalam 12 bulan terakhir dengan prevalensi $53,9 \%$, dan yang menderita LBP dalam 3 bulan terakhir dengan prevalensi $44,4 \%$. Ranking dari bagian-bagian nyeri yang paling banyak dilaporkan secara berurutan adalah: 1) punggung bawah $(22,2 \%)$; 2) bahu (15,1\%); 3) leher $(14,3 \%)$; 4) lutut $(11,7 \%) ; 5)$ pergelangan/tangan $(9,3 \%) ; 6)$ punggung atas $(7,4 \%)$; 7) pinggul $(6,2 \%) ; 8)$ siku $(5,3 \%)$; 9) kaki $(5,0 \%) ; 10)$ pergelangan kaki $(3,5 \%)$.

Berdasarkan penelitian yang dilakukan Community Oriented Program for Controle of Rheumatic Disease (COPORD) bahwa di Indonesia angka kejadian nyeri punggung menunjukan 18,2\% pada laki laki dan 13,6\% pada wanita. National Safety Council melaporkan penyakit akibat kerja yang frekuensi kejadian paling tinggi adalah sakit/nyeri pada punggung, yaitu 22\% dari 1.700 .000 kasus (Tarwaka dkk, 2004 dalam Rinta, 2013).

Hasil penelitian yangdilakukan oleh Persatuan Dokter Saraf Seluruh Indonesia (PERDOSSI) pada pasien diPoliklinik Neurologi Rumah Sakit Cipto Mangunkusumo (RSCM) pada tahun2002 menemukan prevalensi penderita nyeri punggung bawah sebanyak $15,6 \%$.Angka ini berada pada urutan kedua tertinggi sesudah sefalgia dan migren yangmencapai $34,8 \%$. Hasil penelitian secara nasional yang juga dilakukan di $14 \mathrm{kota}$ di Indonesia oleh kelompok studi nyeri PERDOSSI tahun 2002 ditemukan 18,1\% penderita nyeri punggung bawah (Johannes, 2010).

Dinas Tanaman Pangan dan Hortikultura merupakan instansi pemerintahan yang bergerak di bidang pertanian.Cakupan operasi Dinas Tanaman Pangan dan Hortikultura sangat luas meliputi hampir di seluruh wilayah Indonesia.Oleh karena itu, Dinas Tanaman Pangan dan Hortikultura memiliki banyak pekerja di setiap sub bagian dan unit pelaksanaan teknis (UPT). Salah satukantor Dinas Tanaman Pangan dan Hortikulturaterletak di kota Pekanbaru Provinsi Riau di Jl.H.R Soebrantas No 4. Pada unit pelaksanaan teknis terdapat beberapa unit pelaksanaan teknis salah satunya UPT Mekanisasi. UPT Mekanisasi merupakan penggunaan alat dan mesin pertanian (mekanisasi) dalam proses produksi dimaksudkan untuk meningkatkan efisiensi (biaya dan kehilangan hasil panen), efektifitas, produktifitas, kualitas hasil, dan mengurangi beban kerja petani. UPT Mekanisasi juga mempunyai tugas untuk perawatan dan perbaikan alat mesin pertanian. Tugas perawatan dan perbaikan ini dilakukan oleh mekanik. Pada saat melakukan tugasnya (perawatan dan perbaikan alat) banyak mekanik yang melakukan pekerjaannya dengan postur kerja yang tidak alami, seperti: berdiri dan jongkok terlalu lama, membungkuk, dan sebagainya. Hal ini menyebabkan pekerja lebih cepat lelah dan gangguan pada otot rangka salah satunya nyeri punggung bawah (low back pain).

Berdasarkan hasil wawancara awal dengan 8 orang yang dilakukan oleh peneliti kepada mekanik bagian UPT Mekanisasi di Dinas Tanaman Pangan dan Hortikultura Provinsi Riau, bahwa 6orang (75\%) tidak tahu apa itu postur kerja dan 2 orang (25\%) tahu apa itu postur kerja. Sedangkan untuk keluhan low back pain (nyeri punggung bawah/nyeri pinggang) yang dialami pekerja yaitu 2 orang $(25 \%)$ tdak merasakan sakit pada pinggang, 2 orang $(25 \%)$ merasakan agak sakit pada pinggang, 3 orang $(37,5 \%)$ merasakan sakit pada pinggang dan 1 orang (12,5\%) merasakan sangat sakit pada pinggang. Maka dari itu, peneliti tertarik untuk meneliti "Kejadian Low Back Pain pada Mekanikbagian UPT Mekanisasi di Dinas Tanaman Pangan dan Hortikultura Provinsi Riau”.

\section{METODOLOGI PENELITIAN}

Jenis penelitian ini adalah penelitian analitik kuantitatif dengan desain cross sectional. Lokasi yang dipilih untuk melakukan penelitian adalah di bagian UPT Mekanisasi di Dinas Tanaman Pangan dan 
Hortikultura Provinsi Riau, yang dilakukan pada bulan April - Agustus.Sampel dalam penelitian ini adalah seluruh mekanik di bagian UPT Mekanisasi di Dinas Tanaman Pangan dan Hortikultura Provinsi Riaudengan jumlah total sampling 32 orang yang sudah memenuhi kriteria sampel minimal untuk penelitian kuantitatif yaitu 30 responden.Pengumpulan data low back pain dilakukan dengan intrumen berupa body mapping checklistyaitu pemeriksaan 27 titik tubuh responden berdasarkan peta tubuh dengan melalukan penilaian 4 tingkat kesakitan responden (A, $\mathrm{B}, \mathrm{C}$ dan $\mathrm{D})$, dan intrumen pengumpulan data variabel pengetahuan, masa kerja dan umur pekerja adalah dengan kuesioner. Pada variabel pengetahuan terdapat 15 pernyataan tentang bagaimana postur kerja yang baik, akibat poster kerja yang tidak baik dan bagaimana mencegah low back pain. 15 pernyataan ini sudah dilakukan uji validitas dan dinyatakan valid pada pekerja mekanik di Dinas Peternakan Propinsi Riau. Variabel Masa kerja dan umur ditanyakan secara langsung kepada responden sudah berapa lama responden bekerja di tempat tersebut (masa kerja) dan berapa usia responden (umur) saat di lakukan pendataan penelitian. Analisis data yang menggunakan uji regresi linier sederhana.

\section{HASIL PENELITIAN}

\section{Kejadian Low Back Pain Pekerja}

Hasil analisis didapatkan rata-rata keluhan low back pain pekerja adalah 2,56 (95\% CI: 2,16 - 2,96), dengan standar deviasi 1,105. Keluhan terendah yaitu 1(tidak sakit) dan keluhan tertinggi yaitu 4 (sangat sakit). Dari hasil estimasi interval dapat disimpulkan bahwa 95\% diyakini bahwa rata-rata keluhan low back painpekerja adalah diantara 2,16 sampai dengan2,96.

Tabel 1

Distribusi Keluhan Low Back Pain Pekerja Di Bagian UPT Mekanisasi Di Dinas Tanaman Pangan dan Hortikultura Provinsi Riau

\begin{tabular}{ccccc}
\hline Variabel & Mean & SD & $\begin{array}{c}\text { Minimal- } \\
\text { Maksimal }\end{array}$ & $\begin{array}{c}\mathbf{9 5 \%} \\
\text { CI }\end{array}$ \\
\hline $\begin{array}{c}\text { Low Back } \\
\text { Pain }\end{array}$ & 2,56 & 1,105 & $1-4$ & $2,16-$ \\
2,96 \\
\hline
\end{tabular}

Sumber : Analisis Data Primer

\section{Karakteristik Pekerja}

Hasil analisis didapatkan pekerja berumur antara 24 - 55 tahun, mempunyai poin pengetahuna 5 13 poin dan masa kerja 4 - 28 tahun (lihat tabel 2).

Faktor-faktor yang berhubungan dengan LBP

Hasil uji menunjukkan terdapat hubungan yang bermakna $(\mathrm{p}<0.05)$ antara umur dengan kejadian low back pain.Hubungan umur dengan LBP menunjukan hubungan kuat $(\mathrm{r}=0,791)$ dan berpola positif artinya semakin bertambah umur semakin beresiko terjadinya low back pain. Nilai koefisien dengan determinasi 0,625 artinya, persamaan garis regresi yang kita peroleh dapat menerangkan $62,5 \%$ variasi persamaan garis yang diperoleh cukup baik untuk menjelaskan variabel low back pain dan umur pekerja.

Tidak ada hubungan yang signifikan $(p>0.05)$ antara pengetahuan dengan LBP.Hubungan pengetahuan dengan LBP menunjukan hubungan lemah $(\mathrm{r}=0,168)$ artinya semakin baik atau buruknya pengetahuan pekerja tentang postur kerja maka tidak mempengaruhi resiko terjadinya low back pain. Nilai koefisien dengan determinasi 0,028 artinya, persamaan garis regresi yang kita peroleh dapat menerangkan $2,8 \%$ variasi persamaan garis yang diperoleh tidak terlalu baik untuk menjelaskan variabel low back pain dan pengetahuan pekerja.

Hasil uji menunjukkan terdapat hubungan yang bermakna $(\mathrm{p}<0.05)$ antara masa kerja dengan kejadian low back pain.Hubungan masa kerja dengan LBP menunjukan hubungan kuat $(\mathrm{r}=0,796)$ dan berpola positif artinya semakin lama bekerja semakin beresiko terjadinya low back pain. Nilai koefisien dengan determinasi 0,633 artinya, persamaan garis regresi yang kita peroleh dapat menerangkan $63,3 \%$ variasi persamaan garis yang diperoleh cukup baik untuk menjelaskan variabel low back pain dan masa kerja pekerja.

Tabel 2

Distribusi KarakteristikPekerja Di Bagian UPT Mekanisasi Di Dinas Tanaman Pangan dan Hortikultura Provinsi Riau

\begin{tabular}{ccccc}
\hline Variabel & Mean & SD & $\begin{array}{c}\text { Minimal- } \\
\text { Maksimal }\end{array}$ & $\begin{array}{c}\text { 95\% } \\
\text { CI }\end{array}$ \\
\hline Umur & 42,7 & 10,3 & $24-55$ & $39-$ \\
& & & & 46,5 \\
Pengetahuan & 8,5 & 2,8 & $5-13$ & $7,5-$ \\
& & & & 9,5 \\
Masa Kerja & 16,9 & 9,1 & $4-28$ & $13,7-$ \\
& & & & $20,20]$ \\
\hline
\end{tabular}

Sumber : Analisis Data Primer

Tabel 3

Faktor-faktor yang berhubungan dengan Kejadian Low Back Pain di Bagian UPT Mekanisasi di Dinas Tanaman Pangan dan Hortikultura Provinsi Riau

\begin{tabular}{ccccc}
\hline Variabel & $\mathrm{r}$ & $\mathrm{R}^{2}$ & $\begin{array}{c}\text { Persamaan } \\
\text { Garis }\end{array}$ & $\begin{array}{c}\mathrm{P} \\
\text { Value }\end{array}$ \\
\hline Umur & 0,791 & 0,625 & $\begin{array}{c}\mathrm{LBP}=(-1,043) \\
+0,084^{*} \text { umur }\end{array}$ & 0,000 \\
Pengetahuan & 0,168 & 0,028 & $\begin{array}{c}\mathrm{LBP}=1,996+ \\
(0,067) * \text { Pngthn }\end{array}$ & 0,359 \\
Masa Kerja & 0,796 & 0,633 & $\begin{array}{c}\text { LBP }=(0,918) \\
+0,097 * \text { MsKrj }\end{array}$ & 0,000 \\
\hline
\end{tabular}

Sumber : Analisis Data Primer 


\section{PEMBAHASAN}

\section{Hubungan Umur Pekerja dengan Kejadian Low Back Pain}

Penelitian yang dilakukan menunjukkan adanya hubungan yang signifikan antara umur pekerja dengan kejadian low back pain pada pekerja Hasil ini menunjukkan bahwa peningkatan 1 poin umur pekerja maka akanterjadi peningkatan 0,084 poin low back pain pada pekerja.hasil ini menunjukkan bahwa semakin bertambah umur pekerja maka akan semakin beresiko terjadinya low back pain pada pekerja.

Umumnya keluhan otot skeletal mulai dirasakan pada usia kerja yaitu 25-65 tahun. Keluhan pertama biasanya dirasakan pada usia 35 tahun dan keluhan meningkat sejalan dengan bertambahnya umur. Hal ini terjadi karena penurunan kekuatan ketahanan otot sehingga risiko terjadinya keluhan otot meningkat (Jeyaratnam \& Koh, 2009).

Dalam penelitian Louw, Q.A, et al (2007) dalam Halimah (2011) di Afrika ditemukan bahwa populasi yang paling banyak menderita LBP meliputi kelompok usia pekerja/ produktif (48\%). Kelompokusia sekolah yang menderita LBP adalah $15 \%$ dari total penderita LBP. Prevalensi anak-anak dan remaja untuk menderita LBP adalah 33\% sedangkan prevalensi orang dewasa menderita LBP adalah 50\%.

Persentase tersebut diatas dapat bervariasi menurut negara dan populasi, struktur, sosial-ekonomi.Sekitar sepertiga dari populasi umur diatas 45 tahun menderita LBP kronis.LBP merupakan penyebab utama dari suatu ketidak mampuan (disability) pada orang berumur dibawah empat puluh tahun (Rinta, 2013).

Menurut John D (1995) dalam Munir (2012) Nyeri punggung bawah lebih sering mengganggu pada pekerja yang melakukan pekerjaan manual yang berat dan merupakan penyebab utama penyakit serta ketidakmampuan pada pekerja yang berusia 20-40 tahun.Hasil penilitian ini sejalan dengan penelitian Septiawan (2012) umur pekerja terhadap keluhan low back pain, dari 49 responden terdapat 33 responden $(67,3 \%)$ yang berusia lebih dari 35 tahun dan mengalami keluhan LBP. Hal ini menunjukkan lebih dari setengah responden mengalami keluhan LBP.

Hal ini disebabkan karena menurunnya kekuatan ketahanan otot sehingga resiko terjadinya keluhan low back pain pada pekerja akan semakin meningkat.

Hasil penilitian ini sejalan dengan penelitian Septiawan (2012) umur pekerja terhadap keluhan low back pain, dari 49 responden terdapat 33 responden $(67,3 \%)$ yang berusia lebih dari 35 tahun dan mengalami keluhan LBP. Hal ini menunjukkan lebih dari setengah responden mengalami keluhan LBP.

\section{Hubungan Pengetahuan Tentang Postur Kerja dengan Kejadian Low Back Pain}

Penelitian yang dilakukan menunjukkan tidak adanya hubungan yang signifikan antara pengetahuan pekerja tentang postur kerja dengan kejadian low back pain pada pekerja.

Menurut Notoatmodjo (2007) pendidikan seseorang mempengaruhi cara perpikir dalam menghadapi pekerjaan. Dengan pendidikan, manusia dianggap akan memperoleh pengetahuan dan implikasinya. Semakin tinggi pendidikan hidup manusia akan semakin berkualitas, perubahan yang cepat dalam perkembangan ilmu pengetahuan dan teknologi sangat dibutuhkan orang yang berpengetahuan baik. Hal ini juga dikemukan oleh Benny, dkk (1991) dalam Silalahi (2011) menyatakan pada dasarnya pendidikan seseorang mempengaruhi cara berfikir dalam menghadapi pekerjaan, demikian juga sikap dalam menerima program keselamatan dan kesehatan kerja. Namun pada dasarnya, membutuhkan suatu pengalaman dalam bekerja serta di dalam program keselamatan dan kesehatan kerja dalam mencegah terjadinya kecelakaan kerja dari pada pendidikan formal yang didapatkan

Kemungkinan hal ini disebabkan miskonsepsi (misconception) tentang postur kerja. Perilaku dan pemikiran tersebut menyebabkan kebanyakkan responden kurang mengetahui atau mengabaikan tentang postur kerja yang benar dan postur kerja yang salah akan menyebabkan nyeri punggung bawah.

Dari hasil analisa dan teori di atas dapat disimpulkan bahwa pengetahuan responden sedikit banyaknya mempengaruhi tentang nyeri punggung bawah. Hal ini mungkin disebabkan oleh pemaparan sistem edukasi secara umum membuka wawasan dan menimbulkan cara pemikiran yang lebih meluas dan mendalam. Karena perilaku pekerja terhadap cara kerja tersebut yang salah, pekerja tersebut memiliki pengetahuan yang baik tetapi mengabaikan cara kerja yang benar.

\section{Hubungan Masa Kerja dengan Kejadian Low Back Pain}

Penelitian yang dilakukan menunjukkan adanya hubungan yang signifikan antara masa kerja pekerja dengan kejadian low back pain pada pekerja. Semakin lama pekerja tersebut bekerja maka akan semakin berisiko terjadinya low back pain pada pekerja.

Menurut Guo (2004) yang dikutip oleh Kantana (2010) masa kerja adalah faktor yang berkaitan dengan lamanya seseorang bekerja disuatu perusahaan.Terkait dengan hal tersebut, low back pain merupakan penyakit kronis yang membutuhkan waktu lama untuk berkembang dan bermanifestasi.Jadi semakin lama waktu bekerja atau semakin lama seseorang terpajan faktor risiko low back pain ini maka semakin besar pula risiko untuk mengalami low back pain.

Penelitian yang dilakukan oleh Between Lutam (2005) yang dikutip oleh Septiawan (2012) menyatakan bahwa resiko nyeri punggung sangat berhubungan dengan lama kerja.Semakin lama bekerja, semakin tinggi tingkat resiko untuk menderita 
nyeri punggung. Pekerja yang memiliki masa kerja $>5$ tahun memiliki tingkat resiko 7,3 kali lebih besar menderita nyeri punggung dibanding dengan yang memilki masa kerja $<5$ tahun.

Dari hasil analisa dan teori di atas dapat disimpulkan bahwa tingkat kejadian low back pain pada pekerja akan dipengaruhi oleh masa kerja pekerja tersebut. Semakin lama bekerja maka akan semakin beresiko pekerja tersebut mengalami kejadian low back pain.

\section{KESIMPULAN}

Ditemukan hubungan umur pekerja $(r=0,791, p$ $=0,000)$ dan masa kerja $(r=0,796, p=0,000)$ dengan kejadian low back pain pada pekerja bagian UPT Mekanisasi di Dinas Tanaman Pangan dan Hortikultura.

\section{SARAN}

Pekerja lebih menjaga kesehatannya dan menambah wawasannya mengenai aspek-aspek ergonomi terutama tentang postur kerja yang benar melalui pelatihan-pelatihan tentang ergonomi ataupun tentang keselamatan dan kesehatan kerja (K3). Hal ini akan membantu pekerja untuk mengetahui hal-hal apa saja yang dapat mencederai atau membahayakan pekerja itu sendiri, serta mengetahui pencegahan apa saja yang harus dilakukan.

\section{DAFTAR PUSTAKA}

Adhyati, Sari. 2011. Pengaruh Stimulus Kutaneus Slow Stroke Back Massage terhadap Intensitas Nyeri pada Penderita Low Back Pain di Kelurahan Aek Gerger Sidodadi. Skripsi. Medan: USU.

Bukit, Sari. T. 2011. Hubungan Kualitas Tidur dengan Intensitas Nyeri pada Penderita Nyeri Punggung Bawah dan Nyeri Kepala Primer. Tesis. Medan: USU.

Halimah. 2011. Karakteristik Penderita Nyeri Punggung Bawah (NPB) yang Rawat Inap di Rumah Sakit Umum Dr. Pirngadi Medan Tahun 2009-2010. Skripsi. Medan: USU.

Harsono. 1996. Kapita Selekta Neurologi, Edisi Kedua. Yogyakarta: Gadjah Mada University Press.

Jeyaratnam, J dan David Koh. 2009. Buku Ajar: Praktik Kedokteran Kerja. Jakarta: EGC.

Johannes. 2010. Hubungan Antara Postur Tubuh dengan Terjadinya Nyeri Punggung Bawah pada Pasien Poliklinik Neurologi di RSUP H. Adam Malik Medan 2010. KTI. Medan: USU.
Kantana, Trimunggara. 2010. Faktor-Faktor yang Mempengaruhi Keluhan Low Back Pain pada Kegiatan Mengemudi Tim Ekspedisi PT. Enseval Putera Megatrading Jakarta Tahun 2010. Skripsi. Jakarta: Universitas Islam Negeri Syarif Hidayatullah

Koesyanto, Herry. 2013. Masa Kerja Dan Sikap Kerja Duduk Terhadap Nyeri Punggung. Jurnal Kesehatan Masyarakat Universitas Negeri Semarang,http://journal.unnes.ac.id/nju/index. php/kemas.Diakses 27 Februari 2016.

Kurniawati, Dewi. 2013. Taktis Memahami Keselamatan dan Kesehatan Kerja Bidang Teknologi Informasi. Surakarta: Aksarra Sinergi Media.

Kishore, Yashdev. A.R. 2010.Pengetahuan Penarik Becak tentang Nyeri Punggung Bawah Sekitar Universitas Sumatera Utara. KTI. Medan: USU.

Masrah. 2009. Pengaruh Alat Bantu Kerja Dalam Mereduksi Gangguan Muskuloskletal Pekerja Industri Rumah Tangga Pencetakan Batu-Bata di Desa Paya Lombang Kecamatan Tebing Tinggi Kabupaten Serdang Bedagai Tahun 2009. Tesis. Medan: USU.

Munir, S. 2012. Analisa Nyeri Punggung Bawah pada Pekerja Bagian Final Packing dan Part Supply di PT. X Tahun 2012.Tesis. Jakarta: UI.

Nasution, Pahlawan. 2005. Intervensi Lumbar Support (Penyangga Pinggang) terhadap Keluhan Low Back Pain pada Pekerja Pengrajin Bambu Kelurahan Suka Maju Kecamatan Binjai Barat Kota Binjai Tahun 2005. Medan: USU.

Nettina, Sandra. M. 2001. Pedoman Praktik Keperawatan. Jakarta: EGC.

Nurmianto, Eko. 2008. Ergonomi: Konsep Dasar dan Aplikasinya, Edisi Kedua. Surabaya: Guna Widya.

Notoatmodjo. 2003. Ilmu Kesehatan Masyarakat. Jakarta: Rineka Cipta.

Notoatmodjo. 2007. Kesehatan Masyarakat: Ilmu dan Seni. Jakarta: Rineka Cipta.

Purba, Tika. J. 2005. Evaluasi Lingkungan Kerja dan Postur Kerja Ditinjau dari Faktor Ergonomis pada Pekerja Bagian Produksi di PT. UCI Utama Medan Tahun 2005. Medan: USU.

Rinta. 2013. Pengaruh Back Exercise Terhadap Pengurangan Nyeri Punggung Bawah pada Petugas Instalasi Rekam Medik RSUP H.Adam Malik Medan Tahun 2013. Tesis. Medan: USU. 
Santoso, Gempur. 2013. Ergonomi Terapan. Jakarta: Prestasi Pustaka Publisher.

Saryono.2011. Metodologi Penelitian Kesehatan. Yogyakarta: Mitra Cendikia.

Saryano dan Anggraeni.2013. Metodologi Penelitian Kualitatif dan Kuantitatif dalam Bidang Kesehatan. Yogyakarta: Nuha Medika.

Septiawan, H. 2012. Faktor yang Berhubungan dengan Keluhan Nyeri Punggung Bawah pada Pekerja Bangunan di PT Mikroland Property Development Semarang Tahun 2012.Skripsi. Semarang: UNNES.

Silalahi.Lidya 2011.Hubungan Pelaksanaan Program Keselamtan Dan Kesehatan Kerja Dengan
Terjadinya Kecelakaan Kerja Pada PT. Chevron Pacific Indonesia Duri Tahun 2011, Medan : Laporan Tugas Akhir

Sisdiknas. 2003. UU No. 20 Tahun 2003 tentang Sistem Pendidikan Nasional. Jakarta.

Supriyanto. 2011. Perancangan Postur Kerja pada Pekerja Bagian Pencucian dan Penggilingan Kedelai dengan Pendekatan Rapid Entire Body Assesment (REBA) untuk Mengurangi Resiko Musculoskeletal Disorders (MSDs), Medan: Universitas Sumatera Utara.

Wawan \& Dewi. 2011. Teori \& Pengukuran: Pengetahuan, Sikap dan Perilaku Manusia. Yogyakarta: Nuha Medika. 